\title{
Stress and Coping Patterns of Participants and Non-Participants in Self-Help Groups for Parents of the Mentally III
}

\author{
Benjamin Gidron, D.S.W. \\ Neil B. Guterman, M.S.W. \\ Harriet Hartman, Ph.D.
}

\begin{abstract}
The authors examined differences in stress and coping patterns as well as in situationally-related variables between participants and non-participants in selfhelp groups for parents of the mentally ill in Israel. Participants, who were higher on socio-economic status indicators, reported coping patterns that tended to be both more active and interactive. They also reported greater concerns around psycho-social issues than non-participants. The authors discuss the possible interrelationships among these findings.
\end{abstract}

\section{INTRODUCTION}

Self-help groups for families of the mentally ill bring people together for the purpose of mutually assisting one another to cope with and care for mentally ill family members. The expansion of self-help groups and organizations for families of the mentally ill is part of a broader selfhelp movement that has progressed internationally, gathering together

Dr. Gidron is Associate Professor at the Spitzer Department of Social Work, Ben Gurion University of the Negev, Israel. Mr. Guterman is in the Doctoral Program in Social Work and Social Science at The University of Michigan. Dr. Hartman is in the Department of Education, Ben Gurion University of the Negev, Israel. Address requests for reprints to: Spitzer Dept. of Social Work, Ben Gurion University, P.O. Box 653, Beer-Sheva 84120 ISRAEL. 
people who suffer common problems in mutual support (Katz, 1984). It has been suggested that this movement, encompassing thousands of local groups and numerous national-level organizations and clearinghouses, has been spurred on by a failure of formal helping systems to appropriately respond to important unmet health and social needs of those suffering various crises and problems (Strauss, 1987). Increasingly, self-help groups are being recognized by professionals as a major avenue of support for families.

Advocacy by self-help organizations is beginning to have an influence on the way practitioners and researchers approach those in need. With regard to mental illness, for example, it has only been in the last few years that professionals have begun to move away from viewing families predominantly as an etiological factor in an individual's mental illness, toward viewing families primarily as resources for and responders to their mentally ill family member (Spaniol, et al., 1987).

Resulting from this shift have been studies which examine the family's needs and strengths in caring for their mentally ill member. These studies have typically described a severe burden upon family members, one most often involving daily stresses of the sometimes unpredictable and bizarre behaviors of their mentally ill family member, the external stresses of stigma and isolation upon the family, and the oftentimes unresponsive and uninformative interactions with professional mental health helping systems. Further, families have reported that they undergo financial stress, oftentimes feel guilt and exhaustion, as well as a sense of helplessness and hopelessness about their predicament (Gidron \& Guterman, forthcoming; Vine, 1982; Creer \& Wing, 1975; Hatfield, 1978; Potasznik \& Nelson, 1984).

Self-help groups explicitly attempt to address some aspects of such a burden. They typically do so through providing mutual emotional support, self-education both about the illness and coping methods, and practical advice amongst the members, such as where to seek appropriate community resources (Howe \& Howe, 1987). The existing evidence on the helpfulness of self-help participation for families of the mentally ill suggests a number of positive changes. Studies have noted such potential benefits as a reduction in the general sense of burden felt by family members, improved relationships with the mentally ill family member, and an increase in the information on the illness and on coping strategies to address their stresses (Potasznik \& Nelson, 1984; Medvene \& Krauss, 1989; Biegel \& Yamatani, 1986; Shapiro, et al., 1983). 
While these findings are indeed encouraging, it still remains unclear exactly how self-help accrues benefits to parents of the mentally ill. Since evidence suggests that not all parents of the mentally ill join selfhelp groups (Hatfield, 1981), the first question which must be addressed regarding this issue is, "What are the characteristics of those that participate, specifically in terms of their patterns of coping with stress, as well as along central socio-demographic and situational factors?" This study attempts to shed light on this important question by comparing differences between self-help group participants and nonparticipants. Such a comparative approach has not yet been taken with regard to parents of the mentally ill.

What currently exists in the self-help literature on families of the mentally ill is socio-demographic information about participants alone. Some earlier studies have noted that the typical self-help participant tends to be a parent who is middle-aged, educated, and female (Spaniol, et al., 1987; Battaglino, 1987). This profile is similar to descriptions of self-help group participants in other problem areas that, for example, indicate participants most often coming from middle-class backgrounds (Videka-Sherman, 1982; Raiff, 1982; Katz \& Bender, 1976; Lieberman \& Borman, 1979).

This study, for the first time, compares differences between participants and non-participants along socio-demographic variables. In addition, it examines differences between participants and non-participants in self-help groups along stress and coping patterns. Comparing stress patterns can add insight on the specific problems which the two groups of parents experience, and add explanatory power regarding the decision whether to join or not join a self-help group. Comparing coping patterns places self-help participation in the context of other potential coping strategies which the individual may use in dealing with his/her stressful situation.

Finally, no examination to date has specifically looked at self-help group participation in families of the mentally ill outside the United States. Creer and Wing's study (1975) in Britain examined both participants and non-participants in families caring for a mentally ill member, however, no comparisons between the two groups was made at that time. This lack of cultural dimension to the knowledge about self-help is particularly significant as the self-help movement has expanded internationally into developing countries. Thus, the applications and benefits of self-help need to begin to be examined in such different cultural settings. This study, then, examines stress and coping profiles 
of participants versus non-participants outside the United States; namely, of parents of the mentally ill in Israel.

This survey was part of a larger cross-national survey examining selfhelp group participation among parents dealing with various family crises (Chesler, et al., 1988). In Israel, it focused on parents of mentally ill children, and was conducted in conjunction with "Enosh"-the association for the mentally ill in Israel. Enosh is a national voluntary organization comprised primarily, though not exclusively of family members of the mentally ill. Branches of the organization exist in approximately 25 cities and towns in Israel. The branches are engaged in service provision for the mentally ill living in the community by operating a social club several times a week, as well as services to parents or spouses of the mentally ill. These services include a support group, legal advice, and advocacy. The support groups, themselves, primarily engage in emotional support (i.e. discussions surrounding personal feelings and stresses, and ones surrounding the learning of strategies to deal with such concerns), and do not engage in more concrete forms of help such as financial support or advocacy. Finally, Enosh provides educational information on mental illness to the general public.

\section{METHODOLOGY}

Data collection and analysis: Difficulties were encountered in obtaining a representative sample of participants and nonparticipants of parents of the mentally ill, especially the latter group, due to the inordinate stigma concerning mental illness on parents in Israel. With regard to participants in self-help, the five most active Enosh branches were chosen to obtain a sample. Through coordination with Enosh, a member of the research team was invited to attend a meeting of the self-help group in each of the five cities. During the meeting the researcher explained the purpose and procedure of the study. Parents were then asked to sign up for a research interview that later took place in either the parents' homes or the local Enosh offices. Using this procedure, 32 parents were interviewed, with a $0 \%$ refusal rate. The researchers attribute this inordinately low refusal rate to a) the legitimacy given to the researcher by Enosh, and to b) the use of a group medium to obtain the names.

In contrast to this, the researchers needed to employ a different approach to construct an equivalent non-participant comparison (non-control) group. No accurate information exists of the chronically mentally ill living in the community in Israel (Israel Ministry of Health, 1987). Thus, in the same five cities, researchers constructed a comparison group by requesting names from the local Enosh chairperson of parents receiving other support services from Enosh, or from a social worker at the local community mental health clinic. Without the benefits of personal introductions within a group context in 
the participation group, non-participating parents were far more reluctant to discuss their concerns with a researcher. This more indirect approach resulted in a $54 \%$ refusal rate; 18 of 39 parents approached were interviewed.

The interviews lasted one to one-and-one half hours. They covered socio-demographic information on the respondent and his or her child. Self-report data on the impact of the child's mental illness on the respondent's life was collected in a number of domains, including perceived stresses and coping strategies employed. The questionnaire used was the same as that used for the other parent crisis subgroups as part of the larger cross-national study (Chesler, et al., 1988). It was drawn from earlier studies examining the impact of a child's chronic illness on parents (Chesler \& Barbarin, 1987). With regard to perceived stresses, it overlaps most of the domains tapped by subjective Family Burden scales for families of the mentally ill (Platt, 1985; c. f. Potasznik \& Nelson, 1984), such as parents' concerns over treatments, effects on other children, finances, and social network, as well as their more generalized concerns over acceptance and guilt feelings. Adjustments were made to account for likely differences parents might encounter in managing their child's mental illness within Israeli society. The questionnaire was then translated into Hebrew and pretested on a group of parents in an Enosh branch that were not included in the final analysis.

Parents were asked to respond to the degree they felt a wide range of stresses (24 items) likely associated with caring for a mentally ill child. Perceived degree of intensity of a particular stress felt by parents was captured by 5-point Likert-type scales, describing intensity with anchored labels from "not strong at all" to "very strong." Parents were then asked to indicate their perception of the degree that they used a wide range of particular coping strategies to address the stresses they felt (19 items). They answered in degree of frequency they employed their coping strategies. These frequencies were captured by 4-point Likert-type scales, anchored from "often" to "never." Student t-tests on means for independent samples were conducted on the stress and coping means obtained between groups.

Sample characteristics: The interviewees were 50 parents of chronically mentally ill. Of these 50 parents, 32 participated in self-help groups through Enosh, while 18 did not.

The majority of the interviewees were married $(90 \%)$ and female $(62 \%)$. The range in age was between 41 and 82 , with a median of 61 . Ethnic make-up of the sample consisted of $74 \%$ European or American born, while 26\% were born in Asia or Africa. About one quarter (24\%) of the interviewees did not complete elementary school, while $20 \%$ completed 8 years of study. Only $8 \%$ were college educated while the remainder had full or partial high school education. It is important to note here that while this differs from the typical parent of a mentally ill person in other studies, this distribution of education level is not dissimilar to the national average in Israel for this age group. Almost half of the respondents were employed outside the home, primarily the younger respondents. Slightly over half of the respondents considered themselves "religious" or "traditional."

In terms of family size, $21 \%$ had only one child (the mentally ill child), $29 \%$ had 2 children, and the remaining 50\% had 3 or more children (one respondent had 9 children). One third of the respondents lived in dense housing, with an average of more than one person per room.

The majority of the mentally ill children (60\%) were between 26 and 35 years old at the time of the interview. Of the remaining $40 \%, 20 \%$ were between 18 and 25 , and $20 \%$ were 36 years old and older. From the time of the interview, the diagnoses of mental illness (in most cases, schizophrenia) had taken place within the past 5 years for $10 \%$, between 6 and 10 years ago for $24 \%$, between 11 and 20 years ago for $34 \%$, and more 
than 20 years ago for $32 \%$ of the sample. All but $6 \%$ of the mentally ill sons or daughters had been hospitalized at least once. Almost 50\% were hospitalized 4 or more times. At the time of the interview, most of the mentally ill sons or daughters lived in the community: $44 \%$ in their parents' homes, $24 \%$ in their own home or a sheltered home, and $32 \%$ in psychiatric settings.

Since a random control group could not be constructed, the researchers examined for potential characteristic differences between the participant group and the nonparticipant comparison group. Chi-square tests of significance ( $p$ value set at $<.10$ ) were conducted on 11 central socio-demographic and situational variables.

The researchers did not include income as a variable as it is difficult to measure accurately in light of the numerous in-kind services and benefits accorded to some families (e.g. children's allowances, benefits related to military service), and was further confounded by the high inflation rate present at the time of this study.* Other, more stable variables were relied on to tap dimensions of socio-economic status, namely level of education and housing density. These variables are frequently used in official government censuses and in academic studies within Israel are found to be intercorrelated (State of Israel Central Bureau of Statistics, 1987, pp. 122-123; Anson, 1988).

On 8 of the socio-demographic and situational variables, no significiant differences were found. No differences were found between groups on marital status (Chi-square = $.91, \mathrm{df}=2)$, gender (Chi-square $=.04, \mathrm{df}=1)$, age (Chi-square $=2.92, \mathrm{df}=3)$, degree of religiosity (Chi-square $=1.60, \mathrm{df}=3$ ), age of child at diagnosis (Chi-square $=3.76$, $\mathrm{df}=4$ ), time since diagnosis (Chi-square $=1.87$, $\mathrm{df}=1$ ), number of hospitalizations (Chi-square $=7.22, \mathrm{df}=4$ ).

Of the three other variables, significant Chi-square values were found between the participant group and the non-participant comparison group. Those differences included: level of education (Chi-square $=3.34, \mathrm{df}=1, \mathrm{p}<.07$ ), housing density (Chisquare $=3.21, \mathrm{df}=1, \mathrm{p}<.07$ ), and parents previous knowledge about mental illness (Chi-square $=2.95$, df $=1, \mathrm{p}<.09$ ). The differences between participants and nonparticipants are presumed important, and are discussed in further detail below.

\section{RESULTS}

Self-help group participants were found to be significantly different on two central variables related to socio-economic status in Israel: level of education, and housing density. With respect to these variables, participants were found to be from a higher status on both. Of the participants group, $66 \%$ had 9 or more years of formal education, as compared to only $39 \%$ of the non-participants group. Participants came from less dense housing arrangements, with only $25 \%$ living in homes with more than 1 person per room, compared to $50 \%$ of the non-participants. Finally, participants more frequently than non-participants claimed to have had previous knowledge of mental illness prior to diagnosis of their child as mentally ill.

In terms of reported differences in felt levels of stress, summarized in Table 1 below, three specific items were significant below the .10 level.

\footnotetext{
*Because of these reasons, it is not uncommon for income level to be omitted in studies measuring socio-economic status in Israel (c. f. Resh, 1987), and when it is, it is regularly supplemented with measures of level of education and housing density (Weiker, 1983; Ben-Rafael, 1982)
} 


\section{Table 1}

\section{Differences in Stresses Felt between Participants} and Non-Participants (means on 5-point scale, from 1 = "not strong at all" to 5 = "very strong")

\begin{tabular}{|c|c|c|c|c|}
\hline Stress Item & $\begin{array}{l}\text { particp. } \\
\text { mean }\end{array}$ & $\begin{array}{l}\text { non-p. } \\
\text { mean }\end{array}$ & $t$ value & $p$ \\
\hline $\begin{array}{l}\text { Not knowing who to go to for } \\
\text { help }\end{array}$ & 2.91 & 3.78 & 1.91 & .06 \\
\hline Difficulty accepting the situation & 4.50 & 3.83 & -1.94 & .06 \\
\hline Guilt feelings about my child & 2.53 & 1.78 & -1.78 & .08 \\
\hline $\begin{array}{l}\text { Lack of info/knowledge abt the } \\
\text { illness in general }\end{array}$ & 3.06 & 2.78 & & ns \\
\hline $\begin{array}{l}\text { Lack of info abt my child's } \\
\text { specific condition } \\
\text { Concern that child not getting }\end{array}$ & 3.22 & 3.10 & & $\mathrm{~ns}$ \\
\hline $\begin{array}{l}\text { Concern that child not getting } \\
\text { proper treatment }\end{array}$ & 3.06 & 2.83 & & ns \\
\hline Language used by professionals & 2.66 & 2.56 & & ns \\
\hline Keeping up with chores at home & 2.97 & 3.10 & & ns \\
\hline Financial problems & 2.00 & 2.56 & & ns \\
\hline Loss of time and energy at work & $\begin{array}{c}3.22 \\
(\mathrm{n}=23)\end{array}$ & $\begin{array}{c}3.00 \\
(\mathrm{n}=12)\end{array}$ & & ns \\
\hline $\begin{array}{l}\text { Worry about my own mental } \\
\text { health }\end{array}$ & 2.84 & 2.70 & & ns \\
\hline $\begin{array}{l}\text { Worry about my own physical } \\
\text { health }\end{array}$ & 2.47 & 2.78 & & ns \\
\hline Concern about my spouse's health & $\begin{array}{c}3.33 \\
(\mathrm{n}=30)\end{array}$ & $\begin{array}{c}3.12 \\
(\mathrm{n}=16)\end{array}$ & & ns \\
\hline Concern about my child's future & 4.69 & 4.72 & & ns \\
\hline $\begin{array}{l}\text { Concern that if something } \\
\text { happens to me it will be hard }\end{array}$ & & & & \\
\hline $\begin{array}{l}\text { for the rest of family } \\
\text { Relations with my spouse }\end{array}$ & $\begin{array}{l}4.47 \\
2.87\end{array}$ & $\begin{array}{l}4.50 \\
2.37\end{array}$ & & $\begin{array}{l}\text { ns } \\
\text { ns }\end{array}$ \\
\hline $\begin{array}{l}\text { Worry about the effect on other } \\
\text { childr. }\end{array}$ & 2.97 & 2.75 & & ns \\
\hline Time and energy for the family & 2.72 & $\begin{array}{c}2.41 \\
(\mathrm{n}=17)\end{array}$ & & ns \\
\hline $\begin{array}{l}\text { Relations with parents/spouse's } \\
\text { pts. }\end{array}$ & $\begin{array}{c}1.12 \\
(\mathrm{n}=16)\end{array}$ & $\begin{array}{c}1.36 \\
(\mathrm{n}=11)\end{array}$ & & ns \\
\hline Relations with other relatives & $\begin{array}{c}2.06 \\
(\mathrm{n}=31)\end{array}$ & 2.06 & & ns \\
\hline
\end{tabular}


Table 1 (cont.)

\begin{tabular}{lcccc}
\hline \multicolumn{1}{c}{ Stress Item } & $\begin{array}{c}\text { particp. } \\
\text { mean }\end{array}$ & $\begin{array}{c}\text { non-p. } \\
\text { mean }\end{array}$ & t value & $p$ \\
\hline Relations with friends or & & & & \\
$\quad$ neighbors & 2.16 & 2.11 & $\mathrm{~ns}$ \\
Relations with professional staff & 2.56 & 2.72 & $\mathrm{~ns}$ \\
Contact with public agencies & 1.97 & 2.17 & $\mathrm{~ns}$ \\
$\begin{array}{l}\text { Reactions of society towards } \\
\quad \text { myself and my family }\end{array}$ & 3.59 & 3.00 & $\mathrm{~ns}$ \\
\hline
\end{tabular}

These items included: 1) "not knowing who to go to for help," participants reporting weaker stress levels than non-participants; 2) "difficulty accepting the situation," participants reporting stronger stress levels than nonparticipants; and 3) "guilt feelings about my child," participants reporting stronger stress levels than non-participants. Although not significantly different, it is also important to emphasize that on the stigma item, "reactions of society towards myself and my family," as well as on the item, "relations with my spouse," participants reported a higher stress value than non-participants. Also, on the item, "financial problems," nonparticipants reported a higher stress value than participants.

With regard to differences reported in coping strategies used by parents to address their burden, a number of significant differences were found, as summarized in Table 2 below. Non-participants reported that they tended to do nothing about their burden more frequently than selfhelp participants. Participants on the other hand reported that they tended to read books and materials more frequently, as well as ask for help from relatives, friends, neighbors, and professionals more frequently than non-participants. Finally, they reported that they tended to seek information from others more frequently than non-participants. Also important to note is that on the items, "talked to my spouse about personal feelings," "talked to family about the problem," "talked about the problem with other people," participants reported a higher frequency of use than non-participants, although differences found were non-significant.

\section{DISCUSSION}

Not surprisingly, the participants interviewed in this study indicated values which suggest that they came from a higher socio-economic 
Table 2

Coping Differences between Participants and Non-participants (on 4 point scale of frequency of use, $1=$ "not at all," 4 = "a lot")

\begin{tabular}{|c|c|c|c|c|}
\hline Coping Item & $\begin{array}{l}\text { particp. } \\
\text { mean }\end{array}$ & $\begin{array}{l}\text { non-p. } \\
\text { mean }\end{array}$ & $t$ value & $p$ \\
\hline I did nothing & $\begin{array}{c}1.23 \\
(\mathrm{n}=31)\end{array}$ & 2.00 & -2.64 & .015 \\
\hline $\begin{array}{l}\text { Read books or other written } \\
\text { material }\end{array}$ & 2.69 & 1.60 & 3.05 & .004 \\
\hline Asked others for information & 2.53 & 1.56 & 3.22 & .003 \\
\hline Asked relatives for help & 2.03 & 1.44 & 2.04 & .048 \\
\hline Asked for professional help & 3.81 & 3.28 & 2.04 & .052 \\
\hline $\begin{array}{l}\text { Asked friends or neighbors for } \\
\text { help }\end{array}$ & 1.84 & 1.50 & & ns \\
\hline $\begin{array}{l}\text { Asked rabbi or other religious } \\
\text { body for help }\end{array}$ & 1.56 & 1.61 & & ns \\
\hline Felt that life must go on & 3.28 & 3.11 & & ns \\
\hline $\begin{array}{l}\text { Tried not to think about the } \\
\text { problem }\end{array}$ & 1.94 & 2.22 & & ns \\
\hline Accepted things as they are & 2.94 & 3.11 & & $\mathrm{~ns}$ \\
\hline Trusted in God & 2.09 & 2.31 & & $\mathrm{~ns}$ \\
\hline Kept it all inside & 2.72 & 2.94 & & $\mathrm{~ns}$ \\
\hline Cried a lot & 2.94 & 2.89 & & $\mathrm{~ns}$ \\
\hline Counted on myself & 3.12 & 2.83 & & $\mathrm{~ns}$ \\
\hline $\begin{array}{l}\text { Changed division of household } \\
\text { chores }\end{array}$ & $\begin{array}{c}1.59 \\
(\mathrm{n}=31)\end{array}$ & 1.72 & & ns \\
\hline Spent more time at work & $\begin{array}{c}2.55 \\
(\mathrm{n}=22)\end{array}$ & $\begin{array}{c}2.44 \\
(\mathrm{n}=12)\end{array}$ & & ns \\
\hline $\begin{array}{l}\text { Talked to my spouse about } \\
\text { personal feelings }\end{array}$ & $\begin{array}{c}3.33 \\
(\mathrm{n}=30)\end{array}$ & $\begin{array}{c}2.88 \\
(\mathrm{n}=17)\end{array}$ & & $\mathrm{ns}$ \\
\hline $\begin{array}{l}\text { Talked to my family about the } \\
\text { problem/subject } \\
\text { Talked about the problem/ }\end{array}$ & 2.72 & 2.31 & & ns \\
\hline subject with other people & 2.56 & 2.17 & & ns \\
\hline
\end{tabular}

status. This is consistent with earlier studies examining this issue which found that participants of self-help groups of families of the mentally ill tend to be educated and middle class (Hatfield, 1981; Spaniol, et al., 1987; Battaglino, 1987). These variables may contribute 
to explanations of the stress and coping differences found between participants and non-participants.

Stress differences: Participants reported having a greater difficulty accepting their predicament with their mentally ill child, and tended to report greater feelings of guilt than non-participants. Additionally, they reported higher levels of stress in relations with their spouses, and in reactions of society towards themselves and their families. Nonparticipants, on the other hand, reported significantly higher levels of stress around not knowing where to go to for help, as well as financial problems. These profiles suggest that non-participants are burdened more by issues that are basic to their daily functioning and survival, and suggest a picture of being unable to utilize necessary helping resources. The participants stress profile, on the other hand, suggests a greater burden focused on internal and psycho-social concerns. Their concerns appear to be centered more around the question of, "How do I live at peace with myself given my situation?"

Socio-economic factors may explain these differences in stress patterns. The higher-educated parents are likely to have less of a need to deal with the more basic issues of survival, and are likely to be more able to access the necessary information about helping resources. As these issues are less pressing to such parents, what remains is the burden of dealing with psycho-social dimensions of the problem.

Coping differences: Whereas findings with regard to differences between participants and non-participants along stress patterns were not very marked, the differences in the coping patterns resulted in more robust findings in magnitude. The direction of these findings is clear as well. Participants reported more frequently employing active and interactive coping strategies, such as reading about the problem, and asking a number of important support network sources for help or information (professionals, friends, neighbors, relatives, and others). This trend is further supported by other non-significant numbers reported. For example, participants reported a higher level of talking with their spouses and to family about problems. On the other hand, nonparticipants were found to be significantly higher on passive strategies such as "doing nothing."

Socio-economic variables again may be important in explaining these differences. Evidence suggests that persons from higher socio-economic status tend to take a more active approach to problems in their world 
and to have a higher sense of self-efficacy (Ilfeld, 1978). Thus it is likely that they would tend to choose self-help participation as well as other similarly active coping strategies to deal with their situation. It is likely that they have more resources such as social connections, interactive skills, and a sense of self-efficacy, which enable them to utilize those types of coping strategies.

Participation in self-help groups can be viewed as another form of interaction, similar to interactions with sources in one's natural helping networks (family, friends, and so forth). As such, it may be depicted as both a consequence as well as a cause of interactive coping responses. Seen as a consequence, people who intrinsically tend to use interactive coping strategies would also therefore more likely be attracted to selfhelp frameworks. Seen as a cause, self-help participation may encourage the utilization of social resources available in one's environment. This latter possibility is consistent with Medvene \& Krauss' (1988) findings of self-help participants reporting increased comfort in talking with others about the problems they face after participation in self-help groups.

If indeed this second possibility has validity, it may suggest a complementary view of self-help in relation to other natural helping networks, through perhaps the development of interactive help-seeking skills. For example, it may help participants address the psycho-social aspects of their crisis by teaching them how to regain access to their natural network from which they may have become isolated.

This facilitating process must be qualified, however. Previous writings examining coping with crisis have suggested that when individuals suffer from such a crisis, they may initially cope by isolating themselves from their natural helping network due to feelings of shame (Beels, 1975) and stigma (Potasznik \& Nelson, 1984). On the other hand, their natural helping network may lack the ability to empathize and therefore appropriately respond to the person's atypical needs (Borkman, 1984). Taken from this viewpoint, self-help has tended to be viewed as a replacement support network for those in crisis, one that, by its nature, is more appropriately able to provide empathy and support because group participants are in the "same boat." However, if the results presented here are interpreted that self-help participation can encourage interactive help-seeking coping strategies, then self-help can potentially be viewed as an ADJUNCT to and an enhancer of (rather than replacement for) help received by natural helping networks.

The notion of self-help as adjunct support to natural helping networks must be examined more carefully. Though the findings here suggest 
that participants perceive themselves as more interactive, they also suggest (though less strongly, with a non-significant difference found) participants simultaneously feeling a greater sense of stigma than nonparticipants. It may be that participants indeed seek out help more often from their natural helping networks; however, in their helpseeking efforts, they expose themselves to greater misunderstanding and therefore experience more instances of perceived rejections by that network. There is evidence that this may indeed take place (Wortman \& Lehman, 1984). As one parent told the interviewers, "my sister did not let her daughter kiss my son because she was afraid that the mental illness was contagious."

Some methodological caution must be made with the findings as reported here. Obstacles were encountered in constructing an adequate comparison group, including a high rate of refusal of those asked to be interviewed. Although the authors attempted to handle the potential sample bias that may have resulted through statistically and theoretically comparing participants on socio-demographic and situational variables, it remains unknown to what degree these findings are generalizable (through significance testing) to the greater population within Israel. However, it must be stressed that the difficulties encountered in this study were not unlike those of other studies of self-help participation versus non-participation (Powell, 1987, p. 30). Secondly, subjective measures such as the questionnaire used here, while providing one important source of information about the experience of stress and coping, should be supplemented by future research using other measures such as outside observer reports, or objective Family Burden scales (Haan, 1982).

\section{CONCLUSION}

This study has attempted to shed further light on characteristics of participants versus non-participants of self-help groups for parents of the mentally ill. The profiles presented here of participants and nonparticipants in self-help for families of the mentally ill describe participants as tending to come from a higher socio-economic status than nonparticipants. These parents reported greater stress in what appear as more psycho-social burdens. Participants more frequently report utilizing active and interactive coping strategies. The non-participants, on the other hand, tending to come for a lower socio-economic status, are 
bothered by more basic burdens of survival; they tend less to use active forms of coping.

The findings of participants' reports of greater use of their natural helping networks hints at an unexplored but important issue: the delicate interplay between self-help network and the natural helping network. Further study of this unexamined issue could provide insight on how to effectively optimize support from both the self-help network and the natural helping network, while at the same time minimizing the likelihood of negative side effects, such as an increase in sense of stigma.

Finally, concerning the relationship between self-help participation and socio-economic status, it appears that such frameworks are less attractive to people from lower socio-economic statuses, who are more bothered by survival issues and who use less active coping strategies to deal with their predicament. From these findings it appears that selfhelp frameworks as they exist today, with primarily a psycho-social focus, may have difficulties attracting persons from lower socioeconomic statuses. If self-help frameworks wish to attract those persons, they would need to more directly address their expressed needs and build on their present coping patterns.

\section{REFERENCES}

Anson, J. (1988). Mortality and living conditions: Relative mortality levels and their relation to the physical quality of life in urban populations. Social Science and Medicine, 27, 9, pp. 901-910.

Battaglino, L. (1987). Family empowerment through self-help groups. In A.B. Hatfield (Ed.), Families of the mentally ill: Meeting the Challenges. New Directions for Mental Health Services, no. 34. (pp. 43-52). San Francisco: Jossey-Bass.

Beels, C.C. (1975). Families and social management of schizophrenia. Schizophrenia Bulletin, 13, 97-118.

Ben-Rafael, G. (1982). The Emergence of Ethnicity: Cultural Groups and Social Conflict in Israel. London: Greenwood Press.

Ben-Tuvia, S. (1987). Classification of Geographical Units according to the socio-economic characteristics of the population, 1983. Census of Population and Housing Publications, No. 15, Jerusalem.

Biegal, D. \& Yamatani, H. (1986). The effect of self-help groups for families of the mentally ill: Research perspectives. In M. Goldstein (Ed.), Schizophrenia-Family, patient and professional: A new partnership. Washington D.C.: American Psychiatric Press, Inc.

Borkman, T. (1984). Strengthening the selectively unsupportive personal and community net works of their members. In A. Gartner \& F. Riessman (Eds.) The Self Help Revolution. New York: Human Sciences Press.

Chesler, M., \& Barbarin, O. (1987). Childhood cancer and the family: Managing the challenge of stress and support. Brunner Mazel.

Chesler, M., Chesney, B.K., Gidron, B., Hartman, H. \& Sunderland, S. (1988). Self-help groups: A comparative international study of social support and social action. Final report submitted to the U.S. Department of Health and Human Resources. 
Creer, C. \& Wing, J. (1975). Living with a schizophrenia patient. British Journal of Medicine, July, 73-82.

Gidron, B. \& Guterman, N. (forthcoming). Stress and coping patterns of parents of the mentally ill. International Social Work Journal.

Haan, N. (1982). The assessment of coping, defense, and stress. In L. Goldberger \& S. Breznitz (eds.), Handbook of Stress, Theoretical and Clinical Aspects. New York: Free Press.

Hatfield, A.B. (1981). Self-help groups for families of the mentally ill. Social Work, 26, 408-413.

Hatfield, A.B. (1978). Psychological costs of schizophrenia to the family. Social Work, 23, 355-359.

Howe, C.W. \& Howe, J.W. (1987). The National Alliance for the Mentally Ill: History and ideology. In A. Hatfield (Ed.), Families of the mentally ill: Meeting the challenges. New Directions for Mental Health Services, no. 34. (pp. 23-24) San Francisco: Jossey-Bass.

Ilfeld, F.W., Jr. (1978). Psychologic status of community residents along major socio-demographic dimensions. Archives of General Psychiatry, 35, 716-724.

Israel Ministry of Health (1987). Report on the institutionalized mentally ill, Division of Mental Health.

Katz, A. (1984). Self help groups: An international perspective. In A. Gartner \& F. Reissman (Eds.) The Self Help Revolution (pp. 233-242). New York: Human Sciences Press.

Katz, A. \& Bender, E. (1976). The strength in us: Self-help groups in the modern world. New York: Franklin Watts.

Lieberman, M.A. \& Borman, L.D. (1979). Self-help groups for coping with crisis: Origins, members, processes, and impact. San Francisco: Jossey-Bass.

Medvene, L. \& Krauss, D. (1989). Causal attributions about psychiatric disability in a self-help group for families of the mentally ill. Journal of Applied Social Psychology, 19, 1413-1430.

Platt, S. (1985). Measuring the burden of psychiatric illness on the family: an evaluation of some rating scales, Psychological Medicine, 15, pp. 383-393.

Potasznik, H. \& Nelson, G. (1984). Stress and social support: The burden experienced by the family of a mentally ill person. American Journal of Community Psychology, 12, 589-607.

Powell, T. (1987). Self-Help Groups and Professional Practice. Silver Springs MD: National Association of Social Workers.

Raiff, N.R. Self-help participation and quality of life-a study of Staff Recovering, Inc., in L.D. Borman, Borck, R. Hess, F.L. Pasquale (Eds.) Helping people to help themselves (pp. 79-90), New York: Haworth.

Resh, N. (1987). Parents' aspirations and their perception by their children as an influencing factor in the educational attainment process. Megamot, 30, 1, pp. 84-92, (Hebrew).

Shapiro, R., Possidente, S.M., Plum, K.C. \& Lehman, A.F. (1983). The evaluation of a support group for families of the chronically mentally ill. Psychiatric Quarterly, 56, 276-285.

Spaniol, L., Jung, H., Zipple, A. M. \& Fitzgerald, S. (1987). Families as a resource in the rehabilitation of the severely psychiatrically disabled. In A.B. Hatfield \& Lefley, H.P. (Eds.) Families of the mentally ill: Coping and adaptation (pp. 167-190), New York: Guilford.

Statistical Abstracts of Israel (1987). Jerusalem: Central Bureau of Statistics.

Strauss, A. (1987). Health Policy and Chronic Illness. Society. 25, 33-39.

Videka-Sherman, L. (1982). Effects of participation in self-help groups for bereaved parents, compassionate friends. In L.D. Borman, Borck, R. Hess, \& F.L. Pasquale (Eds.) Helping people to help themselves (pp. 69-78), New York: Haworth.

Vine, P. (1982). Families in pain. New York: Pantheon.

Weiker, W.F. (1983). Stratification in Israeli Society: Is there a middle grouping? Israel Social Science Research, 1, 2, pp. 30-56.

Wortman, C.B. \& Lehman, D.R. (1984). Reactions to victims of life crises: Support efforts that fail. In I.B. Sarason \& B.R. Sarason (Eds.) Social Support: Theory, Research and Application. The Hague: Martinus Nijof. 